pushing these actions forward within their communities. In addition, the OSPP called upon all Member States and stakeholders to:

1. Appoint national coordinators and task forces for the implementation of open science;

2. Ensure an interoperable scholarly infrastructure in Europe for better sharing of metadata between disciplines and countries;

3. Ensure that the Human Resource Strategy for Researchers (HRS4R) reflects best open science practices on research integrity, researcher evaluation and the public availability of research outputs;

4. Foster open science literacy from primary school through the whole educational system;

5. Implement a Europe-wide campaign to raise awareness and communicate the benefits of open science among decision makers, research and education bodies, private sector, industrial and citizen organisations.

The last meeting of the OSPP took place in Helsinki on 22 October 2019 and addressed mainly the analysis of its task force on new indicators monitoring and supporting the implementation of open science and the next deliverables of the OSPP until the end of its mandate in May 2020.

\section{Response of EPS}

The EPS responded to some of the public consultations on the expert groups' reports and wrote additional position papers [12]. In particular, in its response on the report on 'Future of scholarly publishing and scholarly communication', it was stressed that - as a learned society and publisher - the EPS is indeed concerned with the four key functions: registration, certification, dissemination and preservation. EPS advocates that high-quality peer review must remain a core value in open access publishing. Further, the EPS stressed that the evaluation of researchers and research output must be based on true scientific merit and much less on bibliometric indices and journal prestige with its impact factor. Finally, whereas a strong role for the implementation of open access publishing is attributed by the expert groups to funding agencies, EPS reminded that physics has been at the forefront of disruptive innovations and new paradigms in scholarly communication, thanks to grassroots initiatives from its community such as SCOAP3 of the high energy and particle physics community.

\section{cOAlition S and Plan S}

In September 2018, the "cOAlition S" consortium of European government funding agencies [13] launched the "Plan S" under the leadership of Science Europe, an initiative to ensure that by 2020 all scientific publications resulting from research funded by these bodies must be published in compliant open access journals or repositories. The Plan S, motivated by the Berlin declaration (2003), and built on ten principles, was submitted for consultation to the stakeholders.

\section{Reactions on Plan S}

The plan $S$ generated an avalanche of more than 600 reactions, many claiming that its proposals were going too far, too quickly and were too risky for many researchers. EPS reacted like other organisations to Plan S; its main concerns are related to the pressure for not supporting hybrid journals any more in the future, the limitation of researchers' freedom in choosing where to publish, the exclusion of non-European stakeholders who play an important role in the publishing business, and the too short transition period planned until 2020.

\section{4 \\ The EPS responded to public consultations on expert groups' reports}

\section{Revised Plan S}

As a reaction to the critics, COAlition $S$ published a revised version of the Plan S, maintaining most of its fundamental principles. Among others, these are that open access publishing should be immediate and without embargo, funders should commit to keep open access publications fees at a reasonable level and the support to hybrid journals should happen only if they are part of a transformative agreement with clearly defined endpoints. Among the main modifications in the revised version is an extension of the timeline by one year until 2021 and transformative agreements supported until 2024 with more possible options.

\section{Position of learned societies}

In the revised Plan S, the position of the learned societies, as an essential component of the scholarly infrastructure and many of them relying on subscription revenue, has been well recognised. cOAlition S will help identifying the different models and practical aspects that would support Societies that engage in transformative agreement for their publications. Commercial publishers and library consortia are already signing such transformative agreements that allow researchers to read a publisher's paywalled content while publishing articles in its journals. The negotiation of such deals is rather complex and time consuming for small societies. In fact,'big deals' are today one of the dominant business models in academic publishing but are also rather disputed as seen in Germany and other countries. Finally, more transparency in open access publication fees and their capping is also strongly emphasised in the revised version of Plan S. 


\section{Challenges of Open Science}

What are the barriers and challenges to adopting open science? Often mentioned are the lack of human resources, the additional costs in time and money, the loss of competitive advantage, the concern about extra scrutiny, the lack of policies and incentives, legal issues, copyright and authorship regulation, the still influential role of impact factor of 'prestigious' research journals needed for reputation and career advancement. Clearly, funding agencies and research performing institutions are in the driving seat when it comes to tackling many if not most of these issues. Things start to move, however, as exemplified by the recent call by Dutch public knowledge institutions and funders of research to change the research reward and incentive systems to better value researchers and scholarly output with new metrics [14]. Much work is also still required on the "research data side". Open research data is the second leg of 'open access to scientific information', next to the open access to peer-reviewed publications. Scientific research data include the data underlying publications and/or other data (such as curated but unpublished datasets or raw data). Making research results more accessible to all is seen as a major contribution to better and more efficient science, and to innovation in the public and private sectors, which are the main raisons d'etre of open science. It requires a definition of what data are for each scientific discipline or sub-discipline and raises questions of data management and preservation. It requires to balance openness with the protection of scientific information, commercialisation and Intellectual Property Rights (IPR), privacy concerns, and security. Hence, data may actually mean metadata allowing access to data under licenses in some cases.

\section{Making results accessible to all is a major contribution to better science}

\section{Acceptance of Open Science}

Facing all these challenges successfully will determine the fate of open science. The real measure of success will be the adoption and acceptance of open science by the scientific community at large. Learned societies like EPS have a major role to play, at the interface between scientists and other stakeholders, to reach this objective.

In addition, EPS must face the future of its flagship scientific journal EPL (formerly Europhysics Letters). EPL is a hybrid letter journal with both subscription and partly open access covering all areas of physics. EPL is published under the scientific policy and control of the EPS by EDP Sciences, IOP Publishing and the Italian Physical Society for a partnership of 17 national physical societies. Following the publication of Plan S and the new developments of open science, EPL is also under pressure to flip into a fully open access journal. Intensive discussion is ongoing to find the best strategy for its future, but one thing is clear: all EPS members and physicists in general should really consider publishing in this high-quality journal, regardless of impact factor and other metrics. EPL is a journal by physicists for physicists and deserve to be strongly supported by our community.

\section{References:}

[1] Open Innovation, Open Science, Open to the World - A vision for Europe (May 2016). https://ec.europa.eu/digital-single-market/ en/news/open-innovation-open-science-open-world

[2] OSPP Website: https://ec.europa.eu/research/openscience/ index.cfm?pg=open-science-policy-platform

[3] Open Science Monitor: https://ec.europa.eu/info/ research-and-innovation/strategy/goals-research-andinnovation-policy/open-science/open-science-monitor_en

[4] Impact of Open Science methods and practices on the economics of research and science - Case studies from life, mathematical and social sciences (2016). https://op.europa.eu/en/ publication-detail/-/publication/f17858b3-d9fc-11e5-8fea01aa75ed71a1/language-en/format-PDF/source-109452842

[5] Next-generation metrics - Responsible metrics and evaluation for open science (2017). https://op.europa.eu/en/ publication-detail/-/publication/b858d952-0a19-11e7-8a3501aa75ed71a1/language-en/format-PDF/source-109452911

[6] Evaluation of research careers fully acknowledging Open Science practices - Rewards, incentives and/or recognition for researchers practicing Open Science (2017). https://op.europa.eu/en/publication-detail/-/publication/ 47a3a330-c9cb-11e7-8e69-01aa75ed71a1/language-en/ format-PDF/source-search

[7] Turning FAIR into reality (2018). https://op.europa.eu/en/ publication-detail/-/publication/7769a148-f1f6-11e8-998201aa75ed71a1/language-en/format-PDF/source-109452754

[8] Prompting an EOSC in practice (2018). https://op.europa.eu/ en/publication-detail/-/publication/5253a1af-ee10-11e8b690-01aa75ed71a1/language-en/format-PDF/source109452635

[9] Future of scholarly publishing and scholarly communication (2019). https://op.europa.eu/en/publication-detail/-/ publication/464477b3-2559-11e9-8d04-01aa75ed71a1/ language-en/format-PDF/source-109452500

[10] Indicator frameworks for fostering open knowledge practices in science and scholarship (2019). https://op.europa.eu/en/ publication-detail/-/publication/b69944d4-01f3-11ea-8c1f01aa75ed71a1/language-en/format-PDF/source-108756824

[11] Open Science Policy Platform Recommendations (2018). https://op.europa.eu/en/publication-detail/-/publication/ 5b05b687-907e-11e8-8bc1-01aa75ed71a1/language-en/ format-PDF/source-109453232

[12] EPS website: https://www.eps.org/page/policy_science_res

[13] cOAlition S and Plan S website: https://www.coalition-s.org/

[14] Room for everyone's talent - towards a new balance in the recognition and rewards of academics (2019). https://www.vsnu.nl/en_GB/news-items/nieuwsbericht/ 543-knowledge-sector-takes-major-step-forward-in-newapproach-to-recognising-and-rewarding-academics.html 